European Association for the Development of Renewable Energies, Environment and Power Quality
International Conference on Renewable Energies and Power Quality (ICREPQ’09)

Valencia (Spain), 15th to 17th April, 2009

\title{
A Multi Objective Multi-Stage Particle Swarm Optimization MOPSO Search Scheme for Power Quality and Loss Reduction on Radial Distribution System
}

\author{
Adel M. Sharaf, senior member IEEE \\ Adel A. A. El-Gammal \\ Centre for Energy Systems, University of Trinidad and Tobago UTT \\ E-mail: adel.sharaf@utt.edu.tt, adel.elgammal@utt.edu.tt
}

\begin{abstract}
There is an increasing interest in renewable and green energy sources and the integration of Distributed Generation DG into the power grid system. The problem of optimal capacitor allocation in electric distribution systems involves maximizing energy utilization, feeder loss reduction, and power factor correction. The feeder loss can be separated into two parts based on the active and reactive power loss components. The paper presents a novel method for minimizing the loss associated with the reactive component of branch currents by placing shunt capacitor optimally selected banks. This paper presents a novel technique for capacitor sizing using the Multi objective multi-stage Particle Swarm Optimization MOPSO to determine optimal capacitor sizes in a radial distribution system. The main objective functions are:

1. Minimize the feeder current for feeder loss reduction,

2. Minimum voltage deviation at each bus of the distribution system, and

3. Feeder capacity release.
\end{abstract}

\section{Key words}

Harmonics, optimal capacitor placement, optimal capacitor sizing, Multi objective Particle Swarm Optimization MOPSO; distributed generation, radial systems, power loss,

\section{INTRODUCTION}

Capacitors are widely used in distribution systems for voltage stabilization and reactive power compensation as well as power/energy reduction, voltage regulation and system capacity release [1]. The extent of these benefits depends greatly on how the capacitor banks are placed and sized. The problem of how to place capacitors on the radial distribution system such that these benefits are achieved and/or maximized against the total cost associated with fixed capacitor placement is termed the General Capacitor Placement Problem. The General Capacitor Placement Problem consists of determining the locations to install capacitors, the types and sizes of capacitors to be installed and the control schemes for the capacitor switching such that an objective function is minimized while the load constraints and system operational constraints at varying load levels are satisfied.
The voltage stability problem in distribution networks is becoming more and more critical as electric utilities operate their grid systems at higher capacities. Increasing network loading results in increases in active and reactive power feeder losses. An increase in active power loss represents loss in savings to the utility as well as a reduction in feeder utilization, whereas an increase in reactive power loss causes system voltages to decline, which in turn increases the active power loss and reduces system reliability. Voltage instability may also arise in heavily loaded distribution networks. Initially, an increase in reactive power requirements causes the voltage to decline slowly; however, the system may reach an unstable region where a small increment in load may cause a steep decline in the system voltage. Here, as load power is increased, the distribution network is no longer capable of transmitting the needed power to meet the load. Installing capacitor banks in distribution networks tends to reduce active and reactive power losses, increases feeder utilization, improve power quality and allows for the installation of more loads on existing distribution systems, thus increasing utility savings.

The problem of optimally selection capacitor banks such that the total cost (i.e., investment plus cost of losses) is minimized while technical constraints (e.g., voltage levels, power flow limits) are enforced is of a combinatory nature as a consequence of capacitor sizes and types being discrete type variables. The work reported in [2], [3] constitutes the reference frame from the point of view of classical optimization methods, like Mixed-integer linear programming. More recently, several AI-related techniques, such as genetic algorithms [4-6], simulated annealing [7] and tabu search [8], [9] have been explored. GA is an iterative search algorithm based on natural selection and genetic mechanism. However, GA is very fussy; it contains selection, copy, crossover and mutation scenarios and so on. Furthermore, the process of coding and decoding not only impacts precision, but also increases the complexity of the genetic algorithm. Particle swarm optimization (PSO) is a novel emerging intelligence which was flexible optimization algorithm 
proposed in 1995. There are many common characteristics between PSO and GA. First, they are flexible optimization technologies. Second, they all have strong universal property independent of any gradient information. However, PSO is much simpler than GA, and its operation is more convenient, without selection, copy, and crossover.

The optimal capacitor selection of distribution network capacitors is a challenging problem since it often involves various conflicting objectives and goals. In general, to solve this optimality problem, there are two optimization techniques based on Particle Swarm Optimization (PSO). These two techniques are: 1. Single objective Particle Swarm Optimization SOPSO, and 2. Multi objective Particle Swarm Optimization MOPSO.

The main procedure of the SOPSO is based on deriving a single aggregate objective function using the functional model of the shunt power filter. The single objective function may combine several objective functions using specified or selected weighting factors [10-12]. The objective function is optimized (either minimized or maximized) using the Particle Swarm Optimization (PSO) method to obtain a single near optimal solution. On the other hand, the main objective of the Multi-Objective (MO) problem is finding the set of acceptable (trade-off) Optimal Solutions. This set of accepted solutions is called Pareto front. These acceptable trade-off solutions give more ability to the user to make an informed decision by seeing a wide range of near optimal solutions that are near optimum from an "overall" standpoint. Single Objective (SO) optimization may ignore this trade-off viewpoint [10], which is crucial. This paper presents a new technique for finding the set of trade-off optimal solutions based on Multi objective Particle Swarm Optimization MOPSO. Multi objective Particle Swarm Optimization MOPSO can easily handle constraints of discrete nature. The main advantages of MOPSO method are:

1. It doesn't requires a priori knowledge of the relative importance of the objectives, and

2. There is a set of acceptable trade-off near optimal solutions. This set is called Pareto front [10-12] or optimality trade-off surfaces.

\section{PARTICLE SWARM OPTIMIZATION (PSO)}

Particle swarm optimization (PSO) is an evolutionary computation optimization technique (a search method based on a natural system) developed by Kennedy and Eberhart [13]-[16]. The system initially has a population of random selective solutions. Each potential solution is called a particle. Each particle is given a random velocity and is flown through the problem space. The particles have memory and each particle keeps track of its previous best position (called the $\left.\mathrm{P}_{\text {best }}\right)$ and its corresponding fitness. There exist a number of $\mathrm{P}_{\text {best }}$ for the respective particles in the swarm and the particle with greatest fitness is called the global best $\left(\mathrm{G}_{\text {best }}\right)$ of the swarm. The basic concept of the PSO technique lies in accelerating each particle towards its $P_{\text {best }}$ and $\mathrm{G}_{\text {best }}$ locations, with a random weighted acceleration at each time step.

The most striking difference between PSO and the other evolutionary algorithms is that PSO chooses the path of cooperation over competition. The other optimization algorithms commonly use some form of decimation, survival of the fittest. In contrast, the PSO population is stable and individuals are not destroyed or recreated. Individuals are influenced by the best performance of their neighbors. Individuals eventually converge on optimal points in the problem domain. In addition, the PSO traditionally does not have genetic operators like crossover between individuals and mutation, and other individuals never substitute particles during the run. So, in PSO all the particles tend to converge to the best solution quickly, comparing with GA.

\section{MULTI-OBJECTIVE OPTIMIZATION}

The following definitions are used in the proposed Multi-Objective Optimization (MO) search algorithm:

Def. 1 The general MO problem requiring the optimization of $\mathrm{N}$ objectives may be formulated as follows:

Minimize

$\vec{y}=\vec{F}(\vec{x})=\left[\overrightarrow{f_{1}}(\vec{x}), \overrightarrow{f_{2}}(\vec{x}), \ldots, \overrightarrow{f_{N}}(\vec{x})\right]^{T}$

subject to $\overrightarrow{g_{J}}(\vec{x}) \leq 0 \quad j=1,2, \ldots, M$

where $\vec{x}^{*}=\left[\vec{x}_{1}^{*}, \vec{x}_{2}^{*}, \ldots, \vec{x}_{P}^{*}\right] \in \Omega$

$\vec{y}$ is the objective vector, the $\overrightarrow{g_{j}}(\vec{x})$ represent the constraints and $\vec{x}^{*}$ is a P-dimensional vector representing the decision variables within a parameter space $\Omega$. The space spanned by the objective vectors is called the objective space. The subspace of the objective vectors satisfying the constraints is called the feasible space.

Def. 2 A decision vector $\vec{x}_{1} \in \Omega$ is said to dominate the decision vector $\vec{x}_{2} \in \Omega$ (denoted by $\vec{x}_{1} \prec \vec{x}_{2}$ ), if the decision vector $\vec{x}_{1}$ is not worse than $\vec{x}_{2}$ in all objectives and strictly better than $\vec{x}_{2}$ in at least one objective.

Def. 3 A decision vector $\vec{x}_{1} \in \Omega$ is called Paretooptimal, if there does not exist another $\vec{x}_{2} \in \Omega$ that dominates it. An objective vector is called Paretooptimal, if the corresponding decision vector is Paretooptimal.

Def. 4 The non-dominated set of the entire feasible search space $\Omega$ is the Pareto-optimal set. The Paretooptimal set in the objective space is called Paretooptimal front.

In MOPSO [10-12], a set of particles are initialized in the decision space at random. For each particle i, a position $x_{i}$ in the decision space and a velocity $v_{i}$ are assigned. The particles change their positions and move towards the so far best-found solutions. The nondominated solutions from the last generations are kept in the archive. The archive is an external population, in which the so far found non-dominated solutions are kept. Moving towards the optima is done in the calculations of the velocities as follows: 


$$
\begin{aligned}
& V_{i d}=\omega \times V_{i d}+C_{1} \times \operatorname{rand}_{1}\left(P_{i d}-X_{i d}\right) \\
& \quad+C_{2} \times \operatorname{rand}_{2} \times\left(P_{g d}-X_{i d}\right) \\
& X_{i d}=X_{i d}+V_{i d}
\end{aligned}
$$

Where $P_{i d}, P_{g d}$ are randomly chosen from a single global Pareto archive, $\omega$ is the inertia factor influencing the local and global abilities of the algorithm, $V_{i d}$ is the velocity of the particle $\mathrm{i}$ in the $\mathrm{d}$ th dimension, $c_{1}$ and $c_{2}$ are weights affecting the cognitive and social factors, respectively. $r_{1}$ and $r_{2}$ are two uniform random functions in the range $[0,1]$. According to (5), each particle has to change its position $X_{i d}$ towards the position of the two guides $P_{i d}, P_{g d}$ which must be selected from the updated set of non-dominated solutions stored in the archive. The particles change their positions during generations until a termination criterion is met. Finding a relatively large set of Pareto-optimal trade-off solutions is possible by running the MOPSO for many generations [12]. Figure (1) shows the flow chart of the MultiObjective Particle Swarm Optimization MOPSO.

\section{DISCRETE PARTICLE SWARM OPTIMIZATION (DPSO) [17-18]}

The particle swarm optimization method works by adjusting trajectories through manipulation of each coordinate of a particle. However, many optimization problems are set in a space featuring discrete, qualitative distinctions between variables and between levels of variables. In the binary version of the PSO, the trajectories are changes in the probability that a coordinate will take on binary value $(0$ or 1$)$. Therefore, the main difference between the original PSO and the DPSO is equation (3) replacing equation (2).

$$
\begin{array}{r}
\text { if }\left(\operatorname{rand}(\quad)<S\left(v_{i d}\right)\right) \text { then } x_{i d}=1 \text {; } \\
\text { Else } x_{i d}=0 .
\end{array}
$$

Where $\mathrm{S}(\mathrm{v})$ is a sigmoid limiting transformation function

$$
S(v)=\frac{1}{1+e^{-v}}
$$

and $\operatorname{rand}()$ is a quasi-random number selected from a uniform distribution in $[0.0,1.0]$. In the discrete version, $V^{\max }$ is retained, that is $\left|v_{i d}\right|<V^{\max }$ which simply limits the ultimate probability that bit $x_{i d}$ will take on a binary value. A smaller $V^{\max }$ will allow a higher mutation rate.

\section{PROBLEM FORMULATION}

Fig. 1 depicts the sample distribution network. The distributed type loads are shown in the appendix (table 4). Figures 2, 3 show the original radial distribution feeder and the equivalent generic single-line model (EGSLM) developed by the First Author. All distributed system loads are lumped together as follows:

$$
\begin{aligned}
& P_{L}=\sum_{i=1}^{10} P_{L i} \\
& Q_{L}=\sum_{i=1}^{10} Q_{L i}
\end{aligned}
$$

And the equivalent generic single-line resistance and reactance are computed such that the active and reactive losses for full and reduced networks to be identical. The active and reactive losses are given as follows:

$\begin{aligned} P_{\text {Loss }} & =\sum_{i=1}^{10} R_{i} \frac{P_{i}^{2}+Q_{i}^{2}}{V_{i}^{2}}=R_{e} \frac{P_{o}^{2}+Q_{o}^{2}}{V_{o}^{2}} \\ Q_{\text {Loss }} & =\sum_{i=1}^{10} x_{i} \frac{P_{i}^{2}+Q_{i}^{2}}{V_{i}^{2}}=x_{e} \frac{P_{o}^{2}+Q_{o}^{2}}{V_{o}^{2}}\end{aligned}$

And thus the equivalent resistance and reactance are computed as follows:

$R_{e}=P_{\text {Loss }} \frac{V_{o}^{2}}{P_{o}^{2}+Q_{o}^{2}}$
$x_{e}=Q_{\text {Loss }} \frac{V_{o}^{2}}{P_{o}^{2}+Q_{o}^{2}}$

The distance of the Equivalent Generic Load $\left(l_{e}\right)$ from the substation is determined according to the following electric moment equations:

$l_{P}=\frac{\sum_{i=1}^{10} P_{L i} l_{i}}{\sum_{i=1}^{10} P_{L i}}$

$l_{Q}=\frac{\sum_{i=1}^{10} Q_{L i} l_{i}}{\sum_{i=1}^{10} Q_{L i}}$

$l_{e}=\sqrt{l_{P} l_{Q}}$

Where $l_{e}$ is the geometric mean,

Non linear Load model is assumed to voltage dependent:

$P_{L N}=P_{L o}\left[1+\alpha_{1}\left(\frac{V_{n}}{V_{\text {base }}}\right)^{\beta_{1}}\right]$
$Q_{L N}=Q_{L o}\left[1+\alpha_{2}\left(\frac{V_{n}}{V_{\text {base }}}\right)^{\beta_{2}}\right]$

The selected four Objective Functions are:

1. Minimize the voltage drops:

$$
\begin{aligned}
& \Delta V_{o}=\left(\frac{11 K V}{\sqrt{3}}\right)-V_{o} \\
& \Delta V_{e}=\left(\frac{11 K V}{\sqrt{3}}\right)-V_{e} \\
& \Delta V_{n}=\left(\frac{11 K V}{\sqrt{3}}\right)-V_{n}
\end{aligned}
$$

2. Minimize the Feeder total active power Losses:

$$
J_{\text {Ploss }}=I_{1}^{2} R_{T}+I_{2}^{2} R_{f 1}+I_{3}^{2} R_{f 2}
$$

3. Minimize the Feeder total reactive power losses:

$$
J_{Q l o s s}=I_{1}^{2} X_{T}+I_{2}^{2} X_{f 1}+I_{3}^{2} X_{f 2}
$$

\section{Minimize the cost of the three capacitor banks:}

The mathematical model for feeder loss optimization is based on computing the required capacitance bank size that will minimize the overall cost for the equivalent network. The cost function is given by:

$J_{\text {cost }}=\propto P_{\text {loss }}+\beta Q_{\text {loss }}+\gamma\left(Q_{c o}+Q_{c e}+Q_{c n}\right)$

Where $\alpha, \beta$ and $\gamma$ are the associated equivalent dollar cost of active loss $\left(\mathrm{P}_{\text {Loss }}\right)$, reactive less $\left(\mathrm{Q}_{\text {Loss }}\right)$ and the installed three capacitor banks $\left(\mathrm{Q}_{\mathrm{co}}, \mathrm{Q}_{\mathrm{ce}}, \mathrm{Q}_{\mathrm{cn}}\right)$. 


\section{DIGITAL SIMULATION RESULTS}

The system data studied are shown in Appendix for a $138 \mathrm{kV}$, 5GVA (short circuit level) distribution network. The equivalent $\mathrm{AC}$ system resistance and reactance are shown in the Appendix. The optimal capacitor sizes and their selected locations are shown in the Appendix as well. The test results are presented for the capacitor placement problem on the test system using the solution algorithm proposed in Sec. 3. The selected locations to install fixed capacitors and optimal sizes of the capacitor banks to be installed are shown in table 1 . The results are summarized in Table 2-3. In each Table, the energy losses and the voltage profile of the systems with/without fixed capacitor placement are also included for continuous and discrete constraints. The system cost with/without capacitor placement is outlined in the same Tables. It is obvious that voltage profile, the system cost and energy losses have been greatly improved with proper capacitor placement. The MOPSO optimized solution results in $65 \%$ savings in cost, $84 \%$ reduction in active power losses, $59 \%$ reduction in reactive power losses.

Table 1 selected location of the capacitor banks and PSO optimized Capacitor sizes

\begin{tabular}{|c|c|c|c|}
\hline & $\begin{array}{c}\text { Selected } \\
\text { location }\end{array}$ & $\begin{array}{c}\text { continuous } \\
\text { constraint } \\
\text { case }\end{array}$ & $\begin{array}{c}\text { discrete } \\
\text { constraint } \\
\text { case }\end{array}$ \\
\hline $\mathrm{Co}(\mu \mathrm{f})$ & $\begin{array}{c}\text { at the sending } \\
\text { end }\end{array}$ & 31.73 & 35 \\
\hline $\mathrm{Ce}(\mu \mathrm{f})$ & $\begin{array}{c}\text { at a location of } \\
6.356478 \mathrm{Km}\end{array}$ & 19.14 & 22 \\
\hline $\mathrm{Cn}(\mu \mathrm{f})$ & at the load bus & 44.19 & 40 \\
\hline
\end{tabular}

Table 2 Distribution system operating condition without/with capacitor placement for continuous constraint case

\begin{tabular}{|c|c|c|}
\hline & $\begin{array}{c}\text { Without capacitors } \\
\text { placement }\end{array}$ & $\begin{array}{c}\text { With capacitors } \\
\text { placement }\end{array}$ \\
\hline Voltage profile & $\begin{array}{c}\mathrm{V}_{\min }=0.936758 \\
\mathrm{~V}_{\max }=1.0\end{array}$ & $\begin{array}{c}\mathrm{V}_{\min }=0.977685 \\
\mathrm{~V}_{\max }=1.0\end{array}$ \\
\hline $\begin{array}{c}\text { Real power } \\
\text { losses }\end{array}$ & $1.0 \mathrm{e}+005 * 0.82984$ & $1.0 \mathrm{e}+005 * 0.4507$ \\
\hline $\begin{array}{c}\text { Reactive power } \\
\text { losses }\end{array}$ & $\begin{array}{c}1.0 \mathrm{e}+005 \\
* 2.408675\end{array}$ & $1.0 \mathrm{e}+005 * 1.5158$ \\
\hline $\begin{array}{c}\text { System cost } \\
\text { including } \\
\text { capacitor cost }\end{array}$ & $1.0 \mathrm{e}+008 * 1.29867$ & $1.0 \mathrm{e}+008 * 0.7864$ \\
\hline
\end{tabular}

Table 3 Distribution system operating condition without/with capacitor placement for discrete constraint case

\begin{tabular}{|c|c|c|}
\hline & $\begin{array}{c}\text { Without capacitor } \\
\text { placement }\end{array}$ & $\begin{array}{c}\text { With capacitor } \\
\text { placement }\end{array}$ \\
\hline Voltage profile & $\begin{array}{c}\mathrm{V}_{\min }=0.91395875 \\
\mathrm{~V}_{\max }=0.9917564\end{array}$ & $\begin{array}{c}\mathrm{V}_{\min }=0.9538756 \\
\mathrm{~V}_{\max }=1.00\end{array}$ \\
\hline $\begin{array}{c}\text { Real power } \\
\text { losses }\end{array}$ & $1.0 \mathrm{e}+005 * 0.82984$ & $1.0 \mathrm{e}+005 * 0.498$ \\
\hline $\begin{array}{c}\text { Reactive power } \\
\text { losses }\end{array}$ & $\begin{array}{c}1.0 \mathrm{e}+005 \\
* 2.408675\end{array}$ & $1.0 \mathrm{e}+005 * 1.585$ \\
\hline $\begin{array}{c}\text { System cost } \\
\text { including } \\
\text { capacitor cost }\end{array}$ & $1.0 \mathrm{e}+008 * 1.29867$ & $1.0 \mathrm{e}+008 * 0.8064$ \\
\hline
\end{tabular}

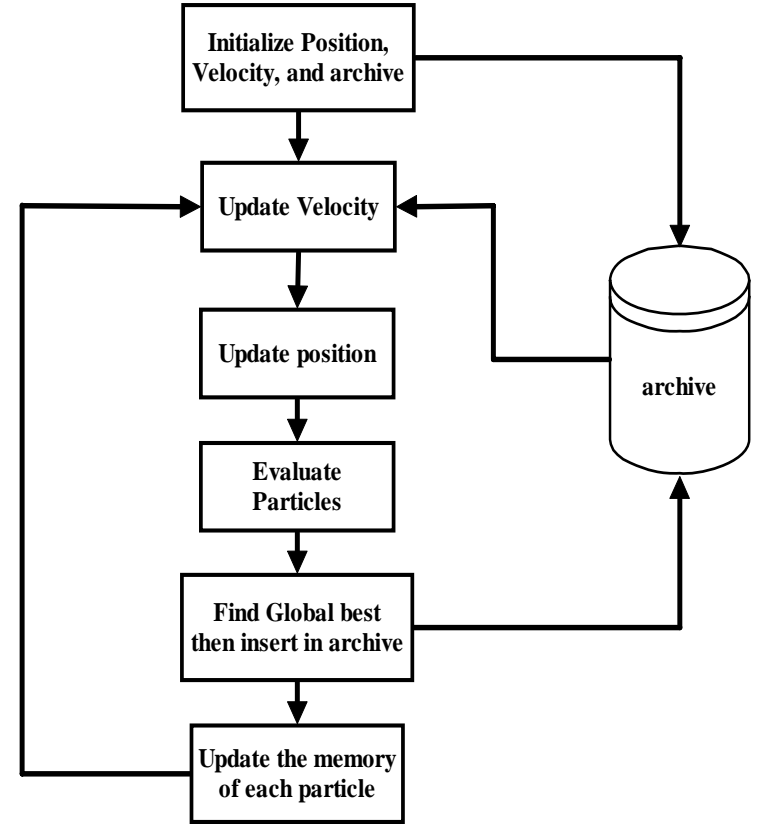

Fig. 1 Flow chart of the MOPSO optimization search algorithm

\section{CONCLUSION}

A novel solution algorithm based on Particle Swarm Optimization PSO for optimal capacitor bank sizes selection in radial distribution networks has been developed and analyzed. The solution search algorithm can provide global optimal solution for the capacitor bank selections. The proposed Multi-Objective optimization technique can deal with different conflicting objectives; with continuous or discrete parameters and/or constraints. The optimization search solution results are a set of near optimal tradeoff values which are called the Pareto front or optimality surfaces. Pareto front enables the utility system operator to choose the best compromise or near optimal solution that reflects a trade-off between key objectives. The iterative simulation results show the effectiveness of the Multi Objective Particle Swarm Optimization approach MOPSO since it allows the operator to find a near optimal good compromise among the proposed goals. Adding capacitor banks to radial distribution feeder results in increased feeder utilization reduced system losses, and enhanced system voltages, capacity release and improved power quality.

\section{APPENDIX}

Non linear Load model Parameters:

$\mathrm{P}_{\mathrm{Lo}}=150 \mathrm{KW}, \mathrm{Q}_{\mathrm{Lo}}=75 \mathrm{KVAR}, \alpha_{1}=0.4, \alpha_{2}=0.25, \beta_{1}=$ $2.5, \beta_{2}=2.0$.

AC System Parameters:

$138 \mathrm{KV}, 5 \mathrm{GVA}$ (short circuit level), $\mathrm{X} / \mathrm{R}=10, \mathrm{X}_{\mathrm{S}}=3.8 \Omega$, $\mathrm{R}_{\mathrm{S}}$ $=0.38 \Omega$.

Distribution Feeder parameters:

$\mathrm{R} / \mathrm{Km}=0.3 \Omega / \mathrm{Km}, \mathrm{X} / \mathrm{Km}=0.35 \Omega / \mathrm{Km}$

Transformer parameters:

$\mathrm{X}_{\mathrm{T}}=6.05 \Omega, \mathrm{R}_{\mathrm{T}}=1.21 \Omega$,

Cost Model Weightings

$\alpha=1000 \$ / \mathrm{KW}, \beta=200 \$ / \mathrm{Kvar}, \gamma=10 \$ / \mathrm{Kvar}$ 
Distributed Loads and Locations

Table 4 the distributed load

\begin{tabular}{|c|c|c|}
\hline $\begin{array}{c}\text { Location }(\mathrm{Km}) \text { from } \\
\text { the reference } \\
\text { position } \mathrm{x}=0\end{array}$ & $\mathrm{P}_{\mathrm{LI}}(\mathrm{KW})$ & $\begin{array}{c}\mathrm{Q}_{\mathrm{LI}} \\
\text { (KVAR) }\end{array}$ \\
\hline 1 & 25 & 12 \\
\hline 2 & 50 & 25 \\
\hline 3 & 75 & 40 \\
\hline 4 & 25 & 12 \\
\hline 5 & 150 & 75 \\
\hline 6 & 250 & 125 \\
\hline 7 & 150 & 75 \\
\hline 8 & 50 & 25 \\
\hline 9 & 75 & 35 \\
\hline 10 & 150 & 75 \\
\hline
\end{tabular}

Load Bus admittance:

$Y_{n}=\frac{1}{R_{n}}+\frac{1}{S X_{n}}+S C_{n}, Z_{n}=\frac{1}{Y_{n}}$

Equivalent distribution network admittance:

$Y_{e}=\frac{1}{R_{e}}+\frac{1}{S X_{e}}+S C_{e}$

Sending end capacitor bank admittance:

$Y_{o}=S C_{o}$

System Impedance:

$Z_{S}=R_{S}+S X_{S}$

Transformer Impedance:

$Z_{T}=R_{T}+S X_{T}$

Feeder Impedances:

$Z_{f 1}=R_{f 1}+S X_{f 1}, Z_{f 2}=R_{f 2}+S X_{f 2}$

Generic Models Equivalent Admittance and Currents

$Y_{n f 2}=\frac{1}{Z_{f 2}+Z_{n}}, Y_{n f 2 e}=Y_{n f 2}+Y_{e}$

$Z_{n f 2 e}=\frac{1}{Y_{n f 2 e}}, Y_{n f 2 e f 1}=\frac{1}{Z_{f 1}+Z_{n f 2 e}}$

$Y_{n f 2 e f 10}=Y_{n f 2 e f 1}+Y_{o}, Z_{n f 2 e f 10}=\frac{1}{Y_{n f 2 e f 10}}$,

$Z_{\text {tot }}=\left(Z_{S}+Z_{T}\right)+Z_{n f 2 e f 1 o}, Y_{\text {tot }}=\frac{1}{Z_{\text {tot }}}$

The feeder currents are:

$I_{1}=\left(\frac{11 K V * 1.05}{\sqrt{3}}\right) * Y_{\text {tot }}$

$I_{2}=I_{1} *\left[\frac{Y_{n f 2 e f 1}}{Y_{n f 2 e f 1 o}}\right], I_{3}=I_{2} *\left[\frac{Y_{n f 2}}{Y_{n f 2 e}}\right]$

The voltages for the equivalent single- line network are given by:

$V_{S}=\left(\frac{11 K V * 1.05}{\sqrt{3}}\right)-I_{1} Z_{S}$

$V_{o}=V_{S}-I_{1} Z_{T}, V_{e}=V_{o}-I_{2} Z_{f 1} \quad, V_{L}=V_{e}-I_{2} Z_{f 2}$

AC Distribution System parameters variations due to switching

$0.025 \leq R_{S} \leq 0.075 \Omega$

$0.7 \leq L_{S} \leq 3 \mathrm{mH}$

Capacitor Banks for the Continues Case:

$300 \leq Q_{c o} \leq 1800$ KVAR

$150 \leq Q_{c e} \leq 750 \quad$ KVAR

$100 \leq Q_{c n} \leq 1500 \mathrm{KVAR}$

Where: $\quad Q_{c}=\omega C V_{L L}^{2}$

Capacitor Banks for the discrete Case:

$Q_{c o} \in\{300,600,1200,1800\} \quad$ KVAR

$Q_{c e} \in\{150,300,450,600,750\} \quad$ KVAR

$Q_{c n} \in\{100,400,700,1000,1500\}$ KVAR

\section{REFERENCE}

[1] Hsiao-Dong Chiang, Jin-Cheng Wang, Orville Cockitigs and Hyoun-Duck Shin " Optimal Capacitor Placements in Distribution Systcins: Part 1: A New
Formulation and the Overall Problem" IEEE Transactions on Power Delively, Vol. 5, No. 2, April 1990

[2] M.E. Baran and F.F. Wu: Optimal capacitor placement on radial distribution Systems. IEEE Trans. on Power Delivery, vol. 4, pp. 725-734, January 1989.

[3] M.E. Baran and EE Wu: Optimal sizing of capacitors placed on a radial distribution system. IEEE Trans. on Power Delivery, vol. 4, pp. 735-743, January 1989.

[4] S. Sundhararajan and A. Pahwa: Optimal selection of capacitors for radial distribution systems using a genetic algorithm. IEEE Trans. Power Systems, vol. 9, no. 3, pp. 1499-1505, Aug. 1994.

[5] D. Das: Reactive power compensation for radial distribution networks using genetic algoritm. Electrical Power and Energy Systems 24 (2002), pp. 573-581.

[6] J. Riquelme Santos, A. Gomez Exposito, J.L. Martinez Ramos" A Reduced-Size Genetic Algorithm for Optimal Capacitor Placement on Distribution Feeders" IEEE MELECON 2004, May 12-15,2004, Dubrovnik, Croatia

[7] H. D. Chiang, J. C. Wang, 0. Cockings, and H. D. Shin: Optimal capacitor placement in distribution systems: Part I, Part 11. IEEE. Trans. Power Delivery, vol. 5, no. 2, pp. 634-649. Apr. 1990.

[8] Y. C. Huang, H. T. Yang, and C. L. Huang: Solving the capacitor placement problem in a radial distribution system using tabu search approach. IEEE Trans. Power Systems, vol. 1 I , no. 4, pp. 1868- 1873, Nov. 1996.

[9] R. A. Gallego, A. J. Monticelli, and Rub\& Romero: Optimal capacitor placement in radial distribution networks. IEEE. Trans. Power Systems, vol. 16, no. 4, pp. 630-637, Nov. 2001.

[10] Ngatchou, P.; Zarei, A.; El-Sharkawi, A.; "Pareto Multi Objective Optimization" Intelligent Systems Application to Power Systems, 2005. Proceedings of the 13th International Conference on 6-10 Nov. 2005 Page(s):84 91

[11] Berizzi, A., M. Innorta, and P. Marannino. "Multiobjective optimization techniques applied to modern power systems". In 2001 IEEE Power Engineering Society Winter Meeting, Jan 28-Feb 12001. 2001.

[12] C. A. Coello Coello and M. S. Lechuga. "MOPSO: A proposal for multiple objective particle swarm optimization". In IEEE Proceedings World Congress on Computational Intelligence,pages1051-1056, 2003.

[13] J. Kennedy and R. Eberhart, "Particle swarm optimization" Proceedings, IEEE International Conf. on Neural Networks, Vol. 4, pp.1942-1948.

[14] Y. Shi and R. Eberhart, "Empirical study of particle swarm optimization" Proceedings of the 1999 Congress on Evolutionary Computation, Vol. 3, 1999.

[15] R. Eberhart and Y Shi, "Particle swarm optimization: developments, applications and resources" Proceedings of the 2001 Congress on Evolutionary Computation, Vol. 1, pp. $81-86,2001$.

[16] Y. Shi and R. Eberhart, "Parameter Selection in Particle Swarm Optimization" Proc. Seventh Annual Conf. on Evolutionary Programming, pp. 591-601, 1998.

[17] Zwe-Lee Gaing "Discrete Particle Swarm Optimization Algorithm for Unit Commitment"; Power Engineering Society General Meeting, 2003, IEEE Volume 1, 13-17 July 2003

[18] J. Kennedy and R. Eberhart, "A Discrete Binary Version of the Particle Swarm Optimization," Proceedings of IEEE International Conference on Neural Netwroks, Vol. IV, pp. 4104-4108, Perth, Australia, 1997. 


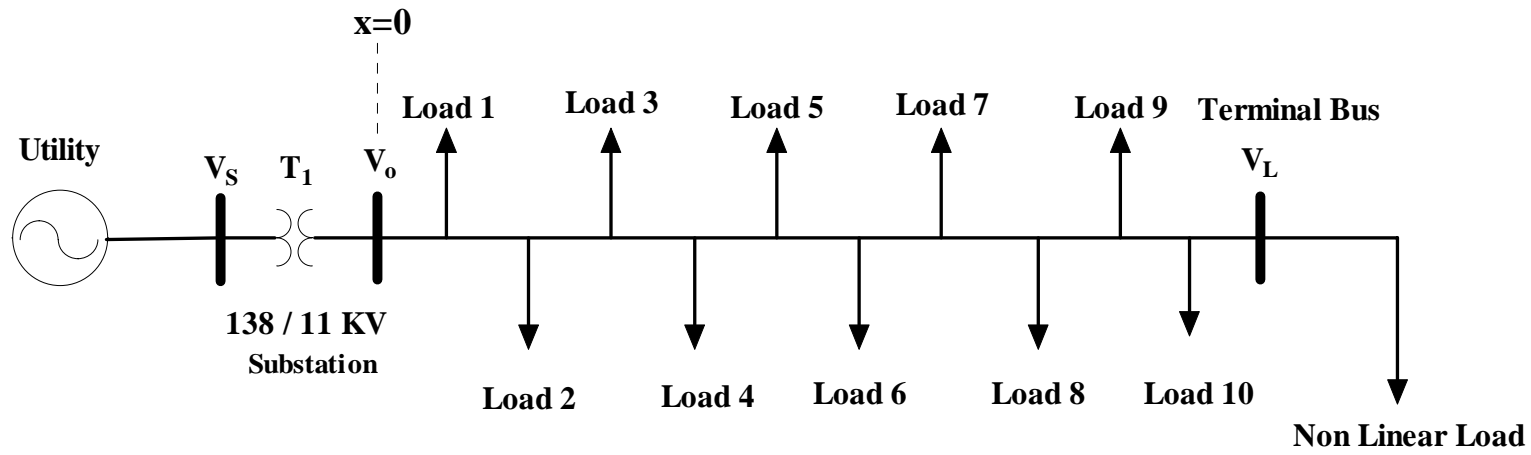

Distributed load 10 Loads / 10 Km

Figure 2: Radial Distribution grid system with Distributed Load

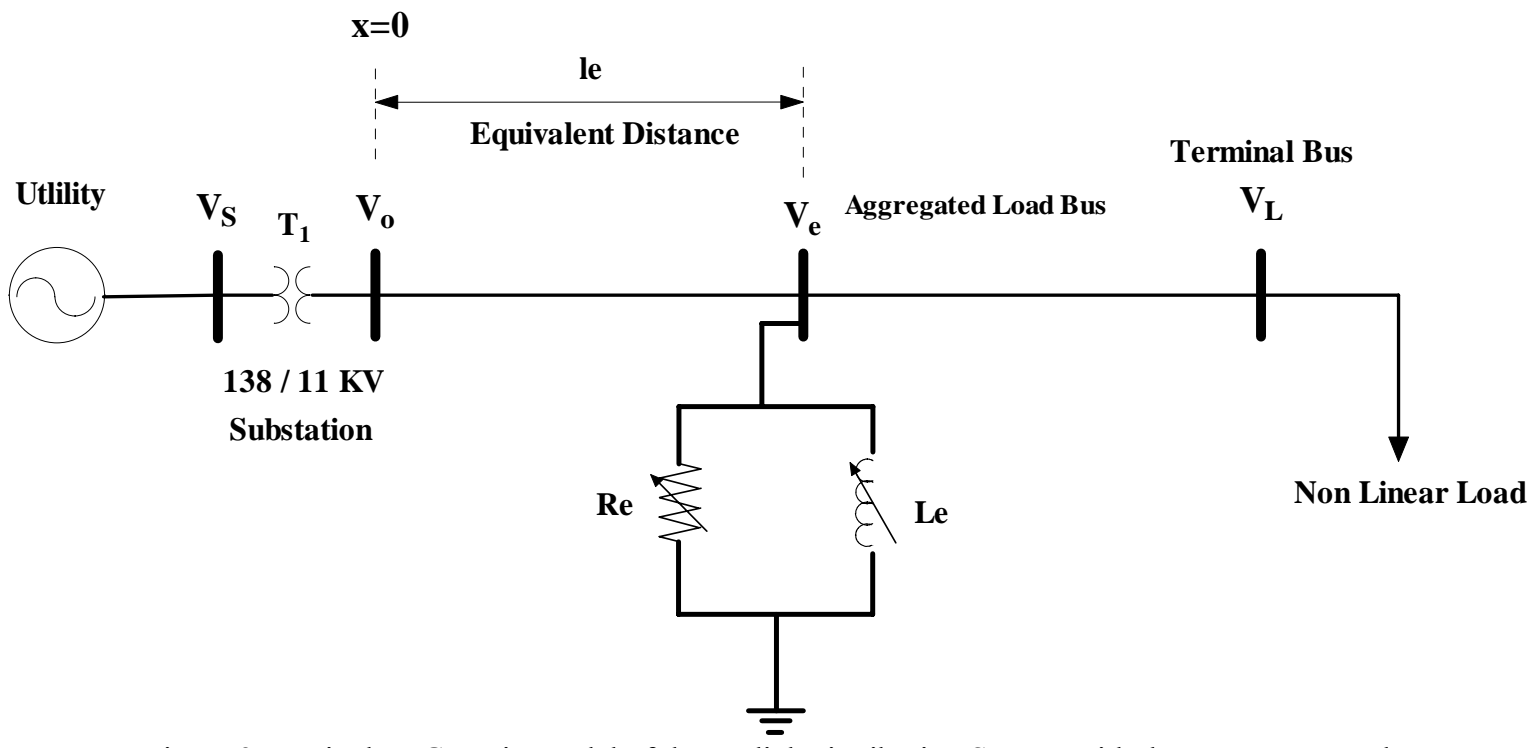

Figure 3: Equivalent Generic Model of the Radial Distribution System with the aggregate Load

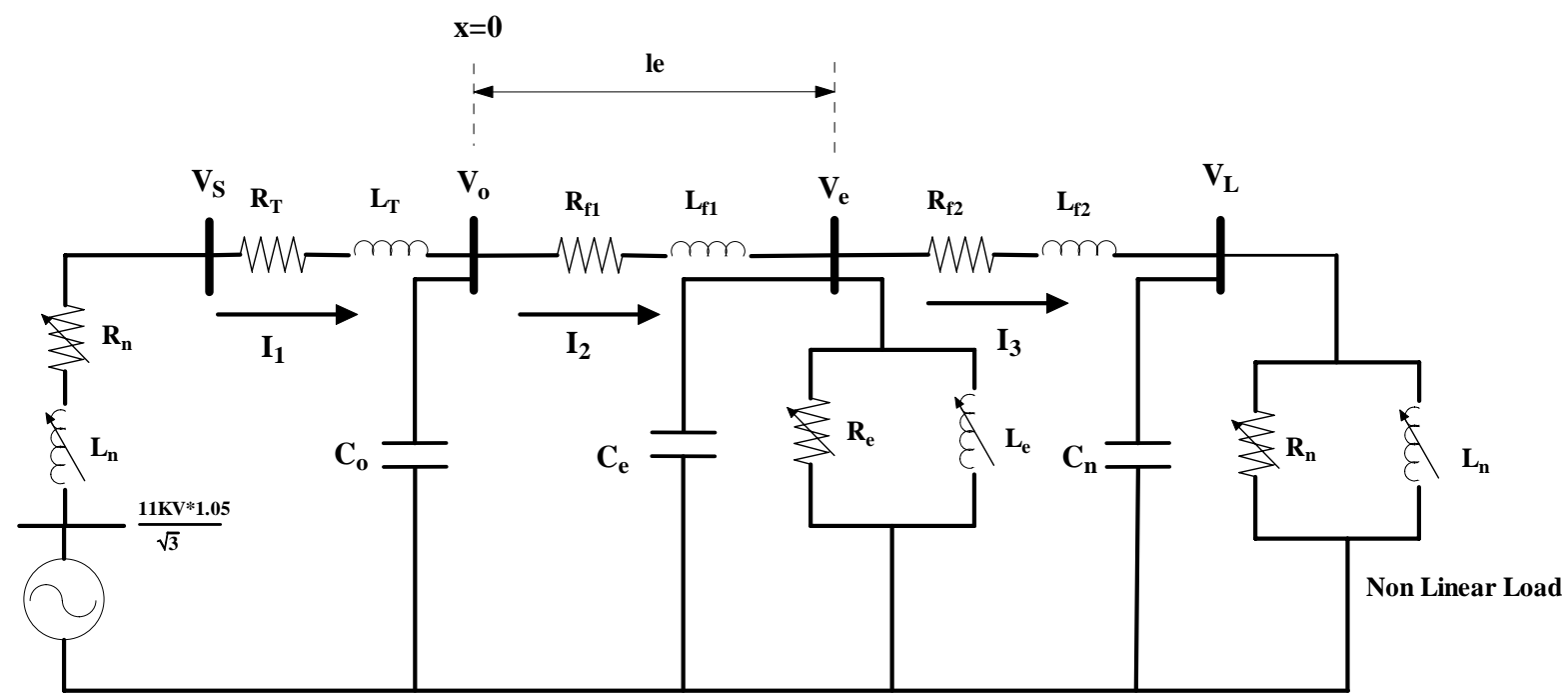

Figure 4: Single Line Diagram of the Equivalent Generic Model of the Radial Distribution System with the aggregate Load 